\title{
Pengembangan E-Evaluation Berbasis Aplikasi Hot Potatoes Untuk Siswa Kelas V Sekolah Dasar
}

\author{
${ }^{*}$ Arnelia Dwi Yasa ${ }^{1}$ Ketut Suastika ${ }^{2}$ Rr. Siti Alisa Nur Zubaidah ${ }^{3}$
}

${ }^{123}$ Program Studi Pendidikan Guru Sekolah Dasar Universitas Kanjuruhan Malang, Malang, Indonesia

\author{
A R T I C L E I N F O \\ Article history: \\ 25 December 2019 \\ Received in revised form \\ 01 January 2020 \\ Accepted 25 January 2020 \\ Available online 28 \\ February 2020 \\ Kata Kunci: \\ E-valuation, Aplikasi Hot \\ potatoes \\ Keywords: \\ E-Evaluation, Hot Potatoes \\ Application
}

\begin{abstract}
A B S T R A K
Hasil rata-rata Ujian Sekolah Berbasis Komputer (USBK) siswa-siswi kelas VI tahun 2018/2019 pada mata pelajaran Matematika mengalami penurunan yang cukup signifikan, dikarenakan siswa belum terbiasa mengerjakan evaluasi pembelajaran berbasis komputer. Tujuan penelitian ini adalah mengembangkan e-evaluation berbasis aplikasi Hot Potatoes yang layak, praktis, dan efektif untuk materi pecahan, FPB, KPK, dan aproksimasi. Penelitian pengembangan ini menggunakan model ADDIE dengan 4 tahapan yang terdiri dari analyze, design, Tahap development, Tahap implementation. Tahap evaluate tidak dilakukan oleh peneliti karena keterbatasan waktu. Validasi produk oleh ahli materi, bahasa, ahli media. Uji coba produk mengukur respon guru kelas $\mathrm{V}$ dan 12 siswa kelas $\mathrm{V}$ SDN Kesatrian 2 Kota Malang. Instrumen observasi, lembar angket, dan dokumentasi. Berdasarkan hasil validasi pada ahli materi memperoleh nilai rata-rata
\end{abstract} $84,6 \%$, ahli media memperoleh nilai rata rata $89,5 \%$, ahli bahasa memperoleh nilai $90 \%$. Hasil angket oleh guru memperoleh $82,8 \%$. Uji coba terbatas pada siswa kelas $\mathrm{V}$ memperoleh $94,8 \%$. Dengan demikian, e-evaluation berbasis aplikasi Hot Potatoes layak, praktis, dan efektif digunakan sebagai evaluasi pembelajaran pada pembelajaran matematika kelas V SDN Kesatrian 2, Kota Malang.

\begin{abstract}
A B S T R A C T
The average score of Computer-Based School Exams (USBK) for grade VI students in academic year 2018/2019 in mathematic had decreased significantly because students were not accustomed to do computer-based learning evaluations. The purpose of this research was to develop an e-evaluation on the basis of Hot Potatoes application. It was feasible, practical, and effective for fractional material, $F P B, K P K$, and approximation. This developmental research used the ADDIE model with 4 stages which was consisted of analyse, design, development, and implementation. The evaluation step was not done by researcher because of time limitation. Product validation was given by material experts, languages, media experts. The trial product measured the response on fifth grade students of elementary school at SDN Kesatrian 2 Malang. Based on the results of the validation on the material experts obtained a mean score of $84.6 \%$, media experts obtained a mean score of $89.5 \%$, linguists obtained a mean score of $90 \%$. The results of the questionnaire by the teacher gained $82.8 \%$. The limited try out for students on fifth grade gained $94.8 \%$. Thus, e-evaluation based on the application of Hot Potatoes was feasible, practical, and effective to be used as an evaluation of learning in mathematic on fifth grade students of SDN Kesatrian 2, Malang.
\end{abstract}

\section{Pendahuluan}

Teknologi informasi memiliki pengaruh yang besar pada kehidupan manusia. Teknologi merupakan sarana yang penting di era revolusi industri 4.0 karena semuanya bisa diperoleh dengan mudah. Teknologi informasi berkembang dengan pesat pada aspek dunia pendidikan. Pendidikan merupakan salah satu aspek terpenting dalam membangun peradaban manusia. Kualitas pendidikan harus ditingkatkan agar dapat mencetak sumber daya manusia yang berkualitas. Menurut Arikunto (2009), untuk mengetahui tingkat ketercapaian kualitas pendidikan yang diharapkan, diperlukan adanya proses evaluasi.

Copyright (C) Universitas Pendidikan Ganesha. All rights reserved. 
Pada evaluasi pembelajaran, guru sering menggunakan evaluasi secara konvensional atau biasa disebut PBT (Paper Based Test). Pada model PBT, guru memberikan soal evaluasi menggunakan lembaran dan menilainya secara manual. Setelah dilakukan evaluasi dengan sistem PBT, guru tidak secara langsung memberikan hasil belajar kepada siswa sedangkan siswa ingin mengetahui hasil belajarnya. PBT memiliki beberapa kelemahan misalnya Untuk sekali menyelenggarakan tes, dibutuhkan biaya cukup mahal untuk biaya cetak dan masih memungkinkan dilakukan kecurangan (Zakaria, Hadiarti, \& Fadhilah, 2017).

Perkembangan teknologi di era revolusi industri 4.0 memberikan dampak terhadap aktivitas belajar dan program pembelajaran sehingga dapat melahirkan berbagai bentuk pembelajaran seperti $o$ learning, e-learning, m-learning, blended learning, distance learning. Teknologi termasuk salah satu aspek penting dalam memperoleh dan mengembangkan ilmu pengetahuan saat ini. Salah satu komponen pembelajaran yang sudah memanfaatkan teknologi adalah evaluasi pembelajaran. Evaluasi pembelajaran yang menguntungkan guru dan siswa yaitu evaluasi yang menggunakan teknologi dalam mengakses informasi sesuai keperluan siswa, baik dari guru dan teman sebaya maupun aplikasi perangkat. Evaluasi berbasis komputer juga merupakan salah satu alternatif mengatasi kurang optimalnya asesmen konvensional (Kamar, Kusair, \& Zubaidah, 2016).

Seiring dengan perkembangan revolusi industri 4.0, guru harus berinovasi menyiapkan lulusannya yang mampu memiliki keterampilan literasi teknologi. Keterampilan tersebut telah menggeser metode evaluasi yang semula dilakukan secara konvensional menjadi metode evaluasi berbasis komputer. Hal tersebut ditandai dengan adanya tes berbantukan komputer. Literasi teknologi menunjukkan kemampuan untuk memanfaatkan teknologi digital dalam mengolah data dan informasi. Tes berbantukan komputer memberikan kemudahan dan inovasi pada literasi teknologi digital. Tes berbantukan komputer saat ini diimplementasikan dalam proses pembelajaran yang ditandai dengan adanya alat evaluasi berbantukan komputer, website dan multimedia (Sadikin, 2019).

Berdasarkan analisis kebutuhan di sekolah, Ujian Sekolah Berbasis Komputer (USBK) di SDN Kesatrian 2 Malang telah dilaksanakan pada bulan Mei Tahun Pelajaran 2018/2019. Hasil yang diperoleh siswa-siswi SDN Kesatrian 2 Malang melalui Ujian Sekolah Berbasis Komputer mengalami penurunan yang cukup siginifikan dari hasil Ujian Nasional Tahun Pelajaran 2017/2018 yang menggunakan sistem Paper Based Test (PBT). Terbukti dari nilai rata-rata Ujian Nasional di SDN Kesatrian 2 Malang tahun pelajaran 2017/2018 untuk mata pelajaran Matematika sebesar 76,22. Sedangkan nilai rata-rata Ujian Sekolah Berbasis Komputer di SDN Kesatrian 2 Malang tahun pelajaran 2018/2019 untuk mata pelajaran matematika mengalami penurunan menjadi 64,39. Hal tersebut dikarenakan beberapa permasalahan antara lain: siswa belum terbiasa mengerjakan ujian atau latihan-latihan soal menggunakan komputer; evaluasi pembelajaran yang digunakan saat ini masih menggunakan mekanisme secara tertulis atau Paper Based Test (PBT); dan siswa masih kebingungan mengerjakan jenis-jenis soal evaluasi tipe Higher Order Thinking Skills (HOTS) dan berbasis Penguatan Pendidikan Karakter (PPK).

Dengan memerhatikan permasalahan tersebut, maka diperlukan suatu evaluasi pembelajaran di kelas berbasis komputer khususnya pada siswa kelas V SDN Kesatrian 2 Malang. Hal tersebut diperlukan agar siswa kelas $\mathrm{V}$ terbiasa mengerjakan soal evaluasi berbasis komputer dengan baik untuk mempersiapkan Ujian Sekolah Berbasis Komputer (USBK) pada kelas VI nantinya. Dengan adanya kebiasaan mengerjakan soal-soal evaluasi menggunakan komputer, maka akan meningkatkan hasil belajar siswa.

Teknologi yang berpotensi untuk membantu tercapainya tujuan evaluasi adalah E-Evaluation berbasis aplikasi Hot Potatoes. Hot potatoes adalah salah satu applikasi pendidikan yang berisi latihanlatihan (Anggoro \& Arif, 2018). E-Evaluation berbasis aplikasi Hot Potatoes dapat melatih kemampuan berpikir kritis dan analisis serta meningkatkan hasil belajar siswa. Kesalahan yang bersumber pada orang yang melakukan penilaian sering dipengaruhi oleh subyektifitas dan kesalahan menjumlahkan angka hasil penilaian. Hal ini dapat diperbaiki dengan suatu E-Evaluation (Electronic Evaluation) yang terintegrasi dengan aplikasi yang secara otomatis dapat mengolah dan menghitung skor hasil belajar peserta didik.

E-Evaluation berbasis aplikasi Hot Potatoes memiliki beberapa keunggulan diantaranya dapat mempermudah guru dalam mengevaluasi proses pembelajaran yang sesuai dengan karakteristik siswa, lingkungan siswa, dan perkembangan kecerdasan siswa. Aplikasi Hot Potatoes ini merupakan tool untuk membuat Bank Soal. Aplikasi ini terdiri atas enam program yang dapat digunakan untuk membuat materi pengajaran secara interaktif berbasis-Web. Program aplikasi ini dilengkapi soal latihan dengan lembar kegiatan siswa (berisi jawaban dan kegiatan siswa) sehingga aplikasi ini bisa digunakan untuk evaluasi pembelajaran di kelas V Sekolah Dasar. Hot potatoes, yang merupakan software yang bisa digunakan guru untuk membuat latihan-latihan berbasis interaktif (Widyastuti, 2018).

Penelitian tentang pengembangan evaluasi yang pernah dilakukan oleh Oduntan, Odunayo Esthe, Adeyanju, Olusayo, \& Omidiora (2015), menunjukkan bahwa kinerja peserta didik ketika menggunakan 
sistem penilaian berbasis komputer atau Computer Based Test (CBT) semakin baik dibandingkan kinerja dari peserta didik ketika menggunakan sistem penilaian berbasis kertas. Sistem evaluasi yang dilakukan dalam penelitian tersebut hanya menggunakan jenis soal-soal pilihan ganda. Selanjutnya hasil penelitian Balan, (2017) menyatakan bahwa model Computer Based Test (CBT) yang dikembangkan relevan dan kontekstual untuk menjawab tuntutan dan kebutuhan pelaksanaan latihan (drill) tes dan ujian berbantuan komputer karena sejalan dengan kebijakan pemerintah melalui Kementerian Pendidikan dan Kebudayaan untuk melaksanakan Ujian Nasional Berbantuan Komputer (UNBK). Pada penelitian sebelumnya hanya mencakup bentuk tes objektif saja. Jenis soal evaluasi yang tersedia dalam aplikasi tersebut hanya menyalin soal evaluasi dari bank soal pada tahun-tahun sebelumnya, jadi tidak ada variasi dan pengembangan evaluasi dalam penginputan soal pada aplikasi tersebut.

Dari beberapa penelitian terdahulu yang telah dilakukan oleh Oduntan dan Balan dapat disimpulkan bahwa adanya perbedaan yang signifikan terhadap kinerja dan hasil belajar siswa yang menggunakan evaluasi berbasis komputer dengan evaluasi berbasis kertas. Sistem evaluasi berbasis komputer terbukti dapat meningkatkan kinerja dan hasil belajar siswa dibandingkan sistem evaluasi berbasis kertas. Pada hasil penelitian yang dikembangakn oleh Oduntan dan Balan menunjukkan bahwa sistem evaluasi yang digunakan hanya berbentuk soal objektif, sedangkan evaluasi yang dibutuhkan pada era digital dan abad 21 saat ini menuntut sistem evaluasi berbasis komputer yang bisa menggali cara berpikir siswa tingkat tinggi atau disebut Higher Order Thinking Skills (HOTS) dan berbasis Penguatan Pendidikan Karakter (PPK). Berdasarkan perbedaan evaluasi berbasis komputer pada penelitian terdahulu dan kebutuhan saat ini, maka E-Evaluation berbasis aplikasi Hot Potatoes penting untuk diteliti dan dikembangkan.

\section{Metode}

Penelitian pengembangan E-Evaluation berbasis aplikasi Hot Potatoes ini dilaksanakan dengan menggunakan model penelitian Research and Development (R\&D) model ADDIE. (Masturah, 2018) mengemukakan bahwa tahapan-tahapan siklus R\&D model ADDIE yaitu, Analysis, Design, Developmen, Implementation dan Evaluation.

Analysis Siswa kelas V SDN Kesatrian 2 membutuhkan evaluasi pembelajaran yang lebih inovatif, media pembelajaran berbasis teknologi atau komputer, dan program didesain secara tepat dan menarik dengan memberikan gambar dan animasi, pembelajaran sikap/afektif. Agar siswa mendapat pengalaman pembelajaran yang baru, agar proses evaluasi pembelajaran matematika akan lebih menarik dan siswa dapat lebih mudah memahami evaluasi pembelajaran yang berlangsung perlu menggunakan alat atau media pembelajaran (Nurryna, 2009). Design tahap perencanaan yaitu berisi pembuatan flow chart dalam perancangan pembuatan evaluasi pembelajaran yang dibutuhkan pada pembelajaran matematika, pada materi pecahan, FPB, KPK, dan aproksimasi atau pembulatan dengan menggunakan E-Evaluation berbasis aplikasi Hot Potatoes. Gambar di sajikan pada Gambar 1 Flowchart.

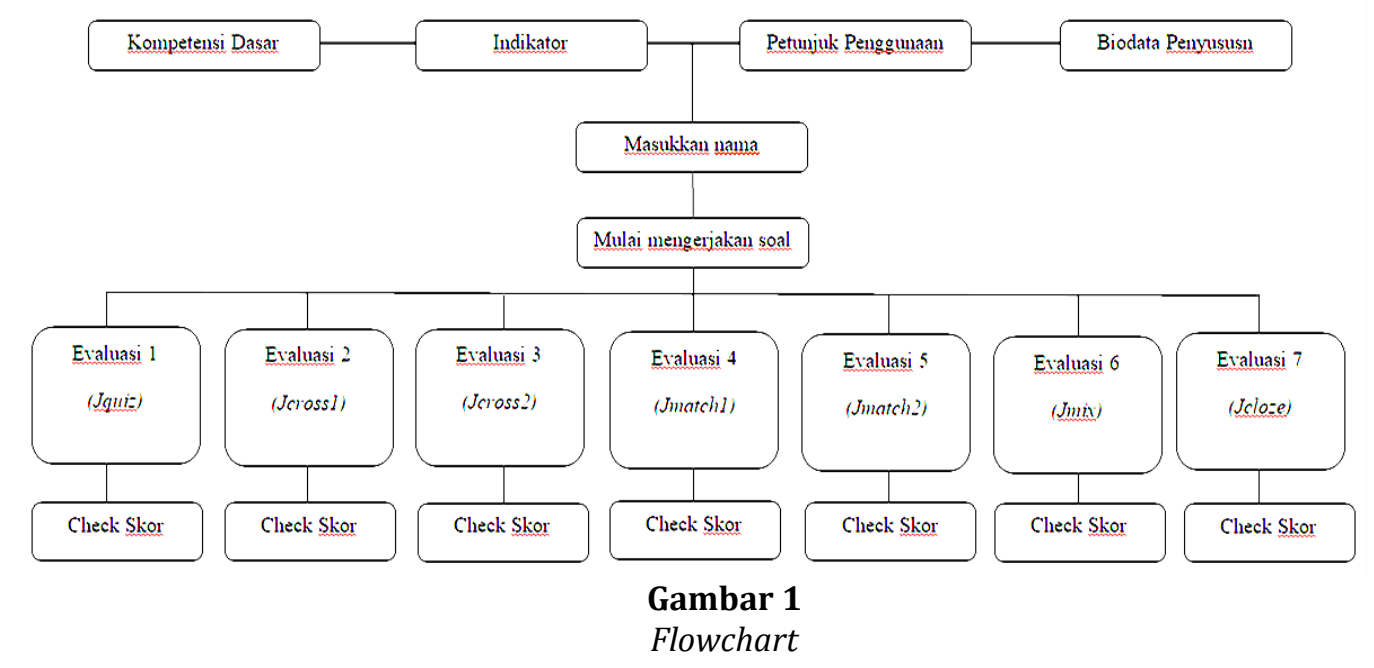

Development yaitu pembuatan produk berdasarkan desain atau rancangan yang telah dibuat. Setelah produk selesai dibuat peneliti melakukan validasi kepada tiga ahli yaitu: ahli media, ahli materi, 
dan ahli bahasa. Validasi yang dilakukan peneliti mendapatkan hasil rata-rata persentase $88,03 \%$ dari hasil rata-rata tersebut peneliti melakukan revisi media lagi sehingga media pembelajaran dapat dikatakan layak untuk di uji cobakan. Implementation, pada tahap ini E-Evaluation berbasis aplikasi Hot Potatoes diimplementasikan pada uji coba lapangan terbatas pada 12 siswa kelas V SDN Kesatrian 2 Kota Malang.

Pada tahap implementasi ini dilakukan untuk mendapatkan data yang dibutuhkan untuk menguji kelayakan E-Evaluation berbasis aplikasi Hot Potatoes. Pada tahap implementasi siswa dapat mengerjakan evaluasi pembelajaran dengan baik dan siswa juga dapat dengan mudah memahami materi pembelajaran, sebab siswa jarang sekali mendapat evaluasi pembelajaran berbasis komputer sehingga siswa dapat termotivasi untuk mengikuti proses kegiatan pembelajaran. Evaluation, tahap evaluasi untuk memperbaiki media yang telah di revisi oleh ahli media dan diterapkan untuk pembelajaran. Pada tahap evaluasi tidak dilakukan oleh peneliti karena keterbatasan waktu.

Penelitian dan pengembangan ini menghasilkan produk E-Evaluation berbasis aplikasi Hot Potatoes untuk mata pelajaran matematika kelas V Sekolah Dasar. Sesuai dengan (Tegeh, 2012) Media E-Evaluation dikembangkan sesuai langkah-langkah model pengembangan ADDIE. ADDIE merupakan kependekan dari Analyze, Desain, Development, Implementation, dan Evaluation..

\section{Hasil dan pembahasan}

Hasil pengujian produk membahas tentang validasi E-Evaluation berbasis aplikasi Hot Potatoes melalui instrumen kelayakan. Instrumen kelayakan ini diberikan kepada ahli media, ahli bahasa dan ahli materi.

Validator memberikan penilaian, komentar dan saran pada lembar validasi yang disusun berdasarkan data yang dibutuhkan oleh peneliti untuk pengembangan produk. Hasil dari penilaian masing-masing validator digunakan sebagai acuan dalam perbaikan media yang dikembangkan. Hasil dari penilaian masing-masing validator dipaparkan pada tabel 1.

Tabel 1. Hasil Kelayakan E-Evaluation berbasis aplikasi Hot Potatoes

\begin{tabular}{cc}
\hline Keterangan & Presentase \\
\hline Ahli Materi & $\mathbf{8 4 , 6 \%}$ \\
Ahli Media & $\mathbf{8 9 , 5 \%}$ \\
Ahli Bahasa & $\mathbf{9 0 \%}$ \\
\hline
\end{tabular}

Validasi media E-Evaluation berbasis aplikasi Hot Potatoes dari ahli media bertujuan untuk mengetahui kelayakan dan pendapat serta saran dari ahli yang berpengalaman di bidang media pembelajaran. Penilaian media E-Evaluation berbasis aplikasi Hot Potatoes terdapat beberapa aspek di antaranya kelayakan ukuran gambar animasi, kelayakan desain display animasi, dan kelayakan desain animasi.

Diketahui bahwa media E-Evaluation berbasis aplikasi Hot Potatoes rata-rata dari keseluruhan aspek mendapat $89,5 \%$. Lembar validasi yang digunakan menggunakan rating scale dengan kriteria penilaian seperti pada tabel 2:

Tabel 2. Rating Scale

\begin{tabular}{|c|c|c|}
\hline No. & Pilihan jawaban & Nilai skala \\
\hline 1. & Sangat tidak baik & 1 \\
\hline 2. & Tidak baik & 2 \\
\hline 3. & Baik & 3 \\
\hline 4. & Sangat baik & 4 \\
\hline
\end{tabular}

(Sugiyono, 2009)

Validasi ahli materi E-Evaluation berbasis aplikasi Hot Potatoes dari ahli materi bertujuan untuk mengetahui kelayakan dan pendapat serta saran dari ahli yang berpengalaman di bidang materi pembelajaran. Penilaian E-Evaluation berbasis aplikasi Hot Potatoes mencangkup beberapa aspek di antaranya kelayakan isi, kelayakan penyajian, kelayakan keterlaksanaan dan kelayakan evaluasi. Berdasarkan penilaian yang diperoleh dari ahli materi. 
Diketahui bahwa materi pada E-Evaluation berbasis aplikasi Hot Potatoes mendapat persentase keseluruhan aspek nilai 84,6\%, dengan kategori "sangat layak" di dukung dengan penelitian yang berjudul "Pengembangan Media Evaluasi Belajar IPA Berbasis Web Offline (Pada Pokok Bahasan Makhluk Hidup dan Proses Kehidupan) Berdasarkan SKL 2013 di Madrasah Ibtidaiyah Imami Kepanjen Malang" memperoleh skor 86,6\%, media termasuk kategori baik, dan media layak untuk diujicoba tanpa revisi. Lembar validasi yang digunakan menggunakan rating scale.

Validasi ahli bahasa E-Evaluation berbasis aplikasi Hot Potatoes dari ahli bahasa bertujuan untuk mengetahui kelayakan dan pendapat serta saran dari ahli yang berpengalaman di bidang bahasa. Penilaian E-Evaluation berbasis aplikasi Hot Potatoes mencakup beberapa aspek di antaranya kelayakan isi, kelayakan penyajian, kelayakan keterlaksanaan dan kelayakan evaluasi. Berdasarkan penilaian yang diperoleh dari ahli bahasa $90 \%$.

Diketahui bahwa bahasa pada E-Evaluation berbasis aplikasi Hot Potatoes mendapat persentase keseluruhan aspek mendapat nilai 90\%, dengan kategori "sangat layak" di dukung dengan penelitian yang berjudul "Pengembangan Media Evaluasi Belajar IPA Berbasis Web Offline (Pada Pokok Bahasan Makhluk Hidup dan Proses Kehidupan) Berdasarkan SKL 2013 di Madrasah Ibtidaiyah Imami Kepanjen Malang" memperoleh skor 86,6\%, media termasuk kategori baik, dan media layak untuk diujicoba tanpa revisi. Lembar validasi yang digunakan menggunakan rating scale.

Hasil validasi untuk pengukuran kepraktisan juga di lakukan oleh guru dan siswa menggunakan menggunakan angket. Hasil aspek disajikan pada Tabel 3 berikut.

Tabel 3. Penilaian respon siswa menggunakan E-Evaluation berbasis aplikasi Hot Potatoes.

\begin{tabular}{l|c}
\hline Aspek yang dinilai & Presentase \\
\hline Kepraktisan siswa & $94,8 \%$ \\
Kepraktisan guru & $82,8 \%$ \\
\hline
\end{tabular}

Berdasarkan hasil pada Tabel 3 dapat diketahui untuk mengukur kepraktisan siswa mendapatkan persentase 94,8\%, yang artinya siswa dan guru dapat dengan mudah menggunakan E-Evaluation berbasis aplikasi Hot Potatoes. Berdasarkan keterangan kriteria analisis kepraktisan, dengan demikian $E$ Evaluation berbasis aplikasi Hot Potatoes dinyatakan "Sangat Praktis". Sejalan dengan penelitian terdahulu yang dilakukan Rahaju \& Semin Rudi Hartono, (2015) dengan judul "Pengembangan monopoli Pembelajaran Matematika Berbasis Permainan Monopoli Indonesia" menunjukkan bahwa hasil tes pada tahap pratindakan, siswa yang tuntas belajar sebanyak 36,7\%, sedangkan pada siklus I sebanyak $60 \%$, dan pada siklus II sebanyak 83,3\%.

Penilaian terhadap hasil tes untuk siswa. Hasil tes siswa dapat dinyatakan tuntas apabila memenuhi Kriteria Ketuntasan Minimal (KKM) yaitu >65 sesuai dengan ketentuan yang diberikan oleh SDN Kesatrian 2. Presentase nilai rata-rata keseluruhan hasil dari tes hasil belajar siswa setelah melakukan evaluasi pembelajaran menggunakan E-Evaluation berbasis aplikasi Hot Potatoes adalah 83,8\% yang dibulatkan menjadi 84\%. Dengan demikian siswa mampu belajar menggunakan E-Evaluation berbasis aplikasi Hot Potatoes dengan nilai melebihi KKM dan pengembangan E-Evaluation berbasis aplikasi Hot Potatoes dapat dikatakan berhasil. Berdasarkan hasil penilaian tersebut tingkat keefektifan yang diperoleh dikategorikan "sangat efektif". Sejalan dengan peneliti terdahulu yang di lakukan (Rahaju \& Semin Rudi Hartono, 2015) dengan judul "Pengembangan monopoli Pembelajaran Matematika Berbasis Permainan Monopoli Indonesia" menunjukkan bahwa hasil tes pada tahap pratindakan, siswa yang tuntas belajar sebanyak 36,7\%, sedangkan pada siklus I sebanyak 60\%, dan pada siklus II sebanyak 83,3\%. Lembar validasi yang digunakan menggunakan skala likert dengan kriteria penilaian pada tabel 4 :

Tabel 4. Skala Likert

\begin{tabular}{cc}
\hline Presentase (\%) & Kriteria Kualitatif \\
\hline $80 \%-100 \%$ & Sangat Baik \\
$66 \%-79 \%$ & Baik \\
$56 \%-65 \%$ & Cukup Baik \\
$0 \%-55 \%$ & Kurang Baik \\
\hline
\end{tabular}

(Arikunto, 2009) 
Dari beberapa validasi dan uji coba yang telah dilakukan, dapat disimpulkan bahwa evaluasi pembelajaran berbasis aplikasi Hot Potatoes yang dikembangkan telah memenuhi kriteria valid, praktis, dan efektif yang dapat digunakan dalam pembelajaran Matematika untuk siswa kelas V sekolah dasar. Dalam hal kepraktiksan temuan ini sejalan dengan penelitian yang menyatakn bahwa aspek usabilitas sangat penting karena aplikasi yang dibuat akan mudah dioperasikan oleh orang awam sekalipun (Fuady, 2016). Selain itu, temuan dalam pengembangan ini didukung dengan penelitian lainnya yang menyatakan bahwa kualitas perangkat pembelajaran khususnya evaluasi yang baik dapat dilihat dari kriteria kevalidan (validity) dan kepraktisan (practically) (Sofnidar dan Husni Sabil, 2012; (Nugroho, Darmi, \& Soneta, 2017))

Pengembangan E-Evaluation berbasis aplikasi Hot Potatoes ini berpotensi memberikan inovasi baru dalam mengevaluasi hasil belajar siswa sehingga penyampaian evaluasi pembelajaran tidak monoton serta dapat menambah wawasan guru untuk mengembangkan evaluasi pembelajaran di era revolusi industri 4.0. Pemanfaatan komputer dalam evaluasi memberikan efektifitas terhadap pelaksanaan tes hasil belajar (Maiziani, 2016). E-evaluation juga merupakan asesmen yang dapat memberikan informasi yang menyeluruh sehingga para pengaar mampu mendapatkan informasi dari peserta didik (Firmansyah, Chandra, \& Aripin, 2019).

\section{Simpulan dan saran}

E-Evaluation berbasis aplikasi Hot Potatoes merupakan produk media yang telah dikembangkan berdasarkan langkah-langkah model penelitian pengembangan ADDIE dengan menggunakan 5 tahapan yaitu Analyze (Analisis) yang meliputi: analisis kurikulum, analisis kebutuhan, dan analisis karakteristik siswa, Design (Desain) yang meliputi: perancangan bahan pembuatan media dan instrumen penelitian, Development (Pengembangan) yang meliputi: pengembangan E-Evaluation berbasis aplikasi Hot Potatoes dan validasi, Implementation (Implementasi) yang meliputi: uji coba produk pada siswa kelas V SDN Kesatrian 2 dan guru kelas V, dan Evaluate (Evaluasi) yaitu pengevaluasian setiap tahapan untuk mengetahui ketercapaian pengembangan E-Evaluation berbasis aplikasi Hot Potatoes. Pada tahap evaluate (evaluasi) tidak dilakukan oleh peneliti karena keterbatasan waktu. Media E-Evaluation berbasis aplikasi Hot Potatoes untuk pembelajaran matematika. Disini peneliti lebih fokus pada pembelajaran matematika materi pecahan, KPK, FPB, dan aproksimasi atau pembulatan. E-Evaluation berbasis aplikasi Hot Potatoes dikategorikan layak digunakan sebagai E-Evaluation berbasis aplikasi Hot Potatoes matematika untuk kelas V sekolah dasar semester I.

\section{Daftar Rujukan}

Arikunto, S. (2009). Prosedur penelitian suatu pendekatan praktik (Edisi Revi). Jakarta: Rineka Cipta.

Anggoro, S. D., \& Arif, M. (2018). The effect of using hot potatoes application in teaching descriptive text. Media of Teaching Oriented and Children, 2(1), 25-33.

Balan, Y. A. (2017). Pengembangan Model Computer Based Test (CBT) Berbasis Adobe Flash untuk Sekolah Menengah Kejuruan. Innovative Journal of Curriculum and Educational Technology, 6(1), 3644.

Firmansyah, S., Chandra, E., \& Aripin, I. (2019). Pengembangan electronic portfolio (e-portfolio) sebagai assessment pembelajaran biologi. Jurnal Bio Educatio, 4(2), 47-57.

Fuady, M. J. (2016). Pengembangan aplikasi evaluasi pembelajaran online untuk pendidikan jarak jauh. Tekno, 2, 148-154.

Kamar, N., Kusair, S., \& Zubaidah, S. (2016). Pengembangan asesmen formatif dan remediasi berbasis komputer pada pokok bahasan suhu dan kalor SMP kelas VII. Jurnal Ilmiah Pendidikan Fisika "Lensa", 4(2), 66-76.

Maiziani, F. (2016). Efektivitas computer based testing sebagai sarana tes hasil belajar. Jurnal Kiprah, 4(1), 15-32.

Masturah. (2018). Pada mata pelajaran IPA kelas III sekolah dasar Setiap warga negara Indonesia, 9, 215225. 
Nugroho, K. U., Darmi, Y., \& Soneta, A. (2017). Pengaruh penerapan e-evaluation dalam pembelajaran terhadap kinerja guru matematika Sma Kota Bengkulu. Jurnal Pendidikan Matematika Raflesia, 2(2), 151-154.

Nurryna, A. F. (2009). Pengembangan Media Pendidikan Untuk Inovasi Pembelajaran. Journal Speed Sentra Penelitian Engineering Dan Edukas, 1(2), 2-6.

Oduntan, Odunayo Esthe, I. A., Adeyanju, S. O., Olusayo, O. \& E., \& Omidiora. (2015). Evaluation of N-gram Text Representations for Automated Essay-Type Grading Systems. International Journal of Applied Information Systems (IJAIS), 9(2), 25-31.

Rahaju \& Semin Rudi Hartono. (2015). Pembelajaran Matematika Berbasis Permainan Monopoli Indonesia. Jurnal Ilmiah Pendidikan Matematika, 2(2).

Sadikin, A. dan N. H. (2019). Pengembangan Media E-Learning Interaktif Dalam Menyongsong Revolusi Industri 4.0 Pada Materi Ekosistem Untuk Siswa SMA. Jurnal Ilmiah Pendidikan Biologi, 5(2), 131138.

Sofnidar dan Husni Sabil. (2012). Pengembangan Bahan Ajar pendidikan Matematika I Dengan Pendekatan Kontekstual. Edumatica, 2(2), 57-67.

Sugiyono. (2009). Metode Penelitian Kuantitatif, Kualitatif dan R\&D. Bandung: Alfabeta.

Tegeh, I. M. \& dan I. M. K. (2012). Pengembangan Bahan Ajar Metode Penelitian Pendidikan Dengan ADDIE Model.

Widyastuti, M. (2018). Penggunaan media elektronik hot potatoes Pada tenaga pengajar bimbingan belajar omega. Faktor Jurnal Ilmiah Kependidikan, 5(3), 213-218.

Zakaria, Hadiarti, D., \& Fadhilah, R. (2017). Pengembangan instrumen evaluasi berbasis cbt dengan software ispring quizmaker pada materi kesetimbangan kimia. Jurnal Pendidikan Matematika dan Sains, 4(2), 178-183. 